\title{
Note sur quelques plantes récoltées pendant la Session extraordinaire et sur un nouveau genre de Composées du Sahara austro-occi- dental;
}

PAR M. J.-A. BATTANDIER.

Les grandes falaises calcaires qui vont du cap Bouak au cap Carbon, près de Bougie, constituent une station botanique très spéciale dont l'exploration a été grandement facilitée par le chemin en corniche récemment creusé dans le roc. Ce n'est que là que l'on trouve le Bupleurum plantagineum Desf., et l'Hypocheris Saldensis Batt. Nous avons eu la chance, au cours de cette session, d'y trouver encore un Silene vivace nouveau extrêmement rare, que nous décrirons ci-après. On trouve aussi dans cette station une curieuse variété du Polycarpon tetraphyllum L. fil., que j'avais autrefois récoltée à l'Est de Delly (Bull. Soc. bot. Fr., 1907, p. 3̈46). Cette variété est remarquable par ses feuilles rondes, son port fastigié et par son aspect terne et gris.

\section{Silene Sessionis nova species.}

Perennis, caudice crassiusculo, multicipite. Caules $20-30 \mathrm{~cm}$. longi, erecti vel patentes, herbacei, subsimplices, rigidiusculi, glabri, internodiis usque ad inflorescentiam paucis, in inflorescentia dichotoma multiflora compactaque valde approximatis. Folia basilaria in rosulam densam disposita, caulina opposita; omnia crassiuscula, glabra vel inferiora basim versus parce cíliata, oblongo-lanceolata, apice acuta, in petiolum longe attenuata, dense punctata glandulis hyalinis. Bracteæ herbaceæ, basi ciliatæ, superiores pubescenti-glandulosæ. Flores erecti breviter pedicellati, in cymam terminalem confertam, e cymulis plerumque trifloris compositam, dispositi. Calyx $20 \mathrm{~mm}$. longus, præsertim in nervis glanduloso-pubescens, tubulosus, haud umbilicatus, capsulæ podogynoque arcte adpressus, albido-membranaceus, nervis 10 filiformibus virentibus, haud prominentibus, versus apicem nervulis paucis anastomosantibus; dentibus longiusculis, triangulari-lanceolatis, acutis, albo-marginatis, breviter ciliatis. Petala ungue calicem excedente, infra limbum distincte auriculata, marginibus glabra, limbo purpureo, die expanso, oblongo-cuneato, apice bilobo, magno, ad faucem lamella bipartita, lobis oblongo-lanceolatis donato. Staminum filamenta glabra. Capsula oblonga, superne paululum attenuata, stipitata stipite capsulæ subæquilongo. Semina reniformia, facie utraque concaviuscula, striata, dorso lato planiusculo, tuberculata. Floret junio. 
A. Battander. - SUR quelques plantes d'afrique.

Cette plante présente de grandes affinités avec le Silene Aristidis Pomel. Elle en diffère par ses tiges moins feuillées et plus courtes, par ses rosettes radicales plus denses et surtout par ses fleurs pourprées d'un diamètre double et son podogyne plus long. Elle se distingue du Silene fruticosa L. par ses feuilles non ciliées, son inflorescence compacte et ses onglets largement auriculés.

Bunium Bulbocastanum L.; Ċarum Bulbucastanum DC.; Bentham et Hooker.

Voilà encore une plante nouvelle pour l'Algérie récoltée au cours de la Session. Munby, il est vrai, signale avec un grand point de doute dans son Catalogue, le Bunium Bulbocastanum à Oran; mais cette plante n'y a jamais été retrouvée, elle n'existe pas dans l'herbier d'Algérie de Cosson. Nous l'avons trouvée très abondante sur les pentes de la montagne à l'entrée des Portes de Fer, en venant de Beni-Mansour. Elle n'était pas complètement identique à la plante de France, assez variable elle-même. Il est très remarquable que, poussant dans une station très aride, elle atteignait parfois la taille d'un mètre. Ses rayons ombellaires longs et très nombreux étaient entièrement lisses. Ses lanières foliaires très longues. Ses achaines, un peu plus courts et plus comprimés par le côté, étaient brusquement tronqués au sommet. Nous proposons d'en faire la variété elatum. Son tubercule avait la grosseur d'une noisette.

Au bas de la même montagne on trouve abondamment une variété du Moricandia suffruticosa DC., remarquable par ses larges feuilles ovales très charnues, les radicales très brièvement pétiolées, les caulinaires embrassantes, et ses grandes fleurs. Cette variété existe aussi à El-Kantara.

M. le $\mathrm{D}^{\mathrm{r}}$ Trabut, directeur du Service botanique du Gouvernement général de l'Algérie, a reçu, il y a peu de temps, du lieutenant Nicloux un envoi de plantes récoltées les unes au Touat, les autres entre les degrés 4 et 10 de longitude occidentale et $23^{\circ}$ et $30^{\circ}$ de latitude. Dans ces dernières se trouvait une petite Composée à aspect d'Asteriscus qui doit constituer un genre nouveau. M. Trabut a bien voulu m'en confier l'étude. 
NIGLOUXIA, novum genus Compositarum e tribu Inuloidearum Bentham et Hooker.

Capitula heterogama, radiata; floribus radii femineis, ligulatis, fertilibus. Flosculi disci hermaphroditi. Involucrum late campanulatum, subhemisphæricum, bracteis pauciseriatis, exterioribus foliaceis spathulatis, interioribus filiformibus, omnibus lanugine densa intertextaque cohærentibus. Receptaculum convexum, onustum paleis persistentibus, dein longissimis (flosculos duplo superantibus) acicularibus, apice scabris, inferne pilosis pilis crispulis longissimis. Ligulæ patentes, tridentatæ. Flosculi regulares, tubulosi, limbo campanulato, 5-fido, glanduloso. Antheræ basi sagittatæ, appendiculatæcaudiculis filiformibus. Styli lineares, hirtuli, apice rotundati. Achænia epapposa, edentulaque, ea ligularum majora cylindrico conica, vellere densissimo crispuloque illis duplo longiori obcondita, ea flosculorum cylindrica glabra.

\section{Niclouxia Saharæ nova species.}

Annua, incano tomentosa, parvula, a radice descendente mox florifera. Caules sub capitulo fere radicali plures decumbentes parce ramosi ramis monocephalis, Capitulis concoloribus aureis, $12-14$ millim. latis. Folia alterna, parva, oblonga basi cuneata subpetiolata, apice mucronata.

Habit : Sahara austro-occidentalis. $\downarrow$.

Cette petite plante, abstraction faite de ses capitules, ressemble presque à un Filago décombant comme le $F$. prolifera Pomel. Elle est très laineuse, ses fleurons sont glanduleux au sommet et sont largement dépassés par les paillettes du réceptacle qui émergent comme une forèt de piques. Les capitules tombent tout d'une pièce et sont incapables de disséminer leurs fruits retenus par une laine épaisse. Ils germent par suite à la manière des fruits de Neurada procumbens, chaque pied emportant fixé à sa racine le capitule dont il est issu.

Je n'ai eu de cette plante que deux pieds trop jeunes. Je n'ai pas vu les achaines des fleurons complètement développés. J'ignore s'ils sont bien conformés ou s'ils demeurent stériles et quelle est la sculpture définitive de leur péricarpe.

A première vue le Niclouxia ressemble à un Asteriscus, mais les caractères de ses achaines et la forme de ses paillettes réceptaculaires ne permettent pas cette réunion. Sa place exacte dans les Inuloïdées paraìt mème assez difficile à fixer.

\section{Explication de la Planche IX.}

Niclouxia Saharx.

1. Plante de grandeur naturelle. - 2. Fleur femelle ligulée grossie. 3. Achaine des ligules dans sa toison de poils très grossi. - 4. Fleuron grossi. - 5. Étamine très grossie. - 6. Styles des fleurons très grossis. 7. Paillette du réceptacle très grossie. 


\section{$2 \mathrm{BHL}$ Biodiversity Heritage Library}

Battandier, Jules Aimé. 1914. "Note sur quelques plantes récoltées pendant la Session extraordinaire et sur un nouveau genre de Composées du Sahara austro-occidental." Bulletin de la Société botanique de France 61, 356-358. https://doi.org/10.1080/00378941.1914.10832585.

View This Item Online: https://www.biodiversitylibrary.org/item/8683

DOI: https://doi.org/10.1080/00378941.1914.10832585

Permalink: https://www.biodiversitylibrary.org/partpdf/161088

\section{Holding Institution}

Missouri Botanical Garden, Peter H. Raven Library

\section{Sponsored by}

Missouri Botanical Garden

\section{Copyright \& Reuse}

Copyright Status: Public domain. The BHL considers that this work is no longer under copyright protection.

This document was created from content at the Biodiversity Heritage Library, the world's largest open access digital library for biodiversity literature and archives. Visit BHL at https://www.biodiversitylibrary.org. 